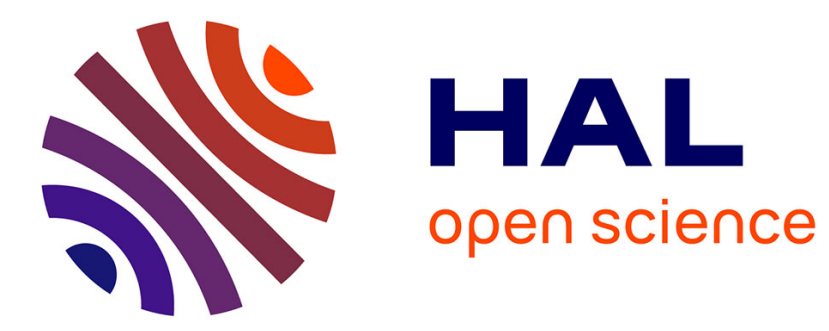

\title{
Comparison and Analysis of Post-Fault Operation Modes in a Five-Phase PMSM Considering Thermal Behavior
}

Hussein Zahr, Mohamed Trabelsi, Eric Semail

\section{- To cite this version:}

Hussein Zahr, Mohamed Trabelsi, Eric Semail. Comparison and Analysis of Post-Fault Operation Modes in a Five-Phase PMSM Considering Thermal Behavior. IEEE 12th International conference on Compatibility, Power Electronics and Power Engineering, Apr 2018, Doha, Qatar. pp.1-6, 10.1109/CPE.2018.8372567 . hal-01858689

\section{HAL Id: hal-01858689 \\ https://hal.science/hal-01858689}

Submitted on 21 Aug 2018

HAL is a multi-disciplinary open access archive for the deposit and dissemination of scientific research documents, whether they are published or not. The documents may come from teaching and research institutions in France or abroad, or from public or private research centers.
L'archive ouverte pluridisciplinaire HAL, est destinée au dépôt et à la diffusion de documents scientifiques de niveau recherche, publiés ou non, émanant des établissements d'enseignement et de recherche français ou étrangers, des laboratoires publics ou privés. 


\title{
Comparison and Analysis of Post-Fault Operation Modes in a Five-Phase PMSM Considering Thermal Behavior
}

\author{
Hussein ZAHR, Mohamed Trabelsi and Eric Semail \\ Univ Lille, Centrale Lille, Arts et Métiers ParisTech, HEI, EA 2697 - L2EP \\ Laboratoire d'Electrotechnique et d'Electronique de Puissance de Lille, F-59000Lille,France \\ Email: hussein.zahr@ensam.eu, mohamed.trabelsi@ensam.eu, eric.semail@ensam.eu
}

\begin{abstract}
This paper presents a comparative evaluation of fault tolerant control strategies for a five-phase Permanent Magnet Synchronous Machine (PMSM) under an opened-phase fault mode. Two main classical Fault Tolerant Control (FTC) methods and the no-reconfiguration strategy are compared with the normal mode operation considering peak current, peak voltage, average torque, torque ripples and measured temperatures of five windings of the five phases. The analysis of the temperature repartition shows that, in fault mode, at least in the particular studied case, the knowledge of the Joule losses is not sufficient for a correct control of the temperature.
\end{abstract}

Keywords-Fault tolerant control, five-phase PMSM, openedphase fault, copper losses, thermal analysis.

\section{INTRODUCTION}

Thanks to their fault tolerance and torque density, the multiphase PMSM are studied in transport applications as automotive [1], aerospace [2], aeronautic [3] and marine [4][5]. Anyway, although a multiphase drive can continue to operate in faulty mode, post-fault operation without reconfiguration of control can lead to some harsh and undesired effects on the machine such as overheating and significant torque ripples. Thus, it is important to reconfigure the control in post-fault operation in order to reduce these effects on the drive. Two main families of FTC have been developed in previous works for the opened-phase fault. In the first family (called MT, as Maximum Torque), the copper losses and the current waveform in the healthy phases are imposed to be equal [6]-[7], inducing then also identical peak currents. The current constraints for the transistors of the Voltage Source Inverter are then easily defined by the peak value. Moreover, when the electromotive forces (emf) are sinusoidal [7]-[8] or with only the first and third harmonics [9] , the torque ripples are also easily controlled and references of current are calculated in order to obtain the maximum torque. In the second family of FTC, the waveforms of the currents are free: for given waveforms of emf and required average torque, the Joule losses are minimized under the constraint of zero torque ripples. The currents are calculated either by optimization approach (as Lagrangian multiplier) in case of sinusoidal [7] but also non-sinusoidal emf [10]-[11] or by a vectorial approach [12]-[13], this last one being more convenient for real-time control and non-sinusoidal emf. With this second family of FTC, the peak currents and voltages can be quite different in the healthy phases, leading to unequal Joule losses even if the global losses are the same as the normal operation. This unbalance between the healthy phases in terms of losses could be considered as an unbalanced thermal constraint between the windings. In fact the proposed paper shows that it is not always the case because it is finally not the losses which are important but the temperatures which are depending not only on the losses but also on the thermal coupling between the windings: even with equal losses in the healthy phases, the temperature is not the same in the healthy phases. In [14], for a given control, an interesting analysis of the temperatures in fault mode obtained by Finite Element simulation has been already achieved and experimental results but in a particular machine configuration is provided. In the proposed paper, an experimental five-phase prototype is considered without particular configuration and the impact on the temperatures of the control in fault mode is presented. It is appearing that the repartition of the Joule losses is not representative of this one of the temperatures. As consequence the elaboration of control strategies based only on the losses is not the best choice in fault mode. It is the reason why in the paper is comparing different FTC considering other criteria than losses. For this studied machine, the results obtained by the two kinds of FTC (called $M_{3}$ and $M_{4}$ similar as in [15]) in terms of torque, torque ripples, peak current, peak voltages and finally temperature of one winding of each phase are presented. They are compared between them and with the healthy case $\left(M_{l}\right)$ and fault case without reconfiguration $\left(M_{2}\right)$.

This paper is organized as follows: after a presentation of the machine in section II, the current waveforms are defined for pre-fault and post-fault operation modes in section III. In section IV, comparative analysis is provided between different classical control strategies based on several parameters related to the machine performance. In section $\mathrm{V}$, a thermal behaviour investigation is pointed out experimentally for each control strategy using thermal resistance detectors installed on some coils in the machine.

\section{FIVE-PHASE PMSM PROTOTYPE AND MODELLING}

The considered machine is a prototype that has been achieved in the frame of an industrial project for $48 \mathrm{~V}$ low 
voltage hybrid automotive application. Fig.1-a and Fig.1-b show the 20-slot/14-pole five-phase PMSM [16], in which fractional slot tooth concentrated winding and IPM rotor are used.

In order to characterize the thermal behaviour especially in fault mode the prototype has been equipped of several temperature sensors. The location of the resistance thermal detector (RTD) is depicted in Fig.1-b. One RTD is inserted for each phase. It is placed on one coil among the four coils forming each phase winding. These coils are labelled by the phase to which they belong with the subscription $c 1$, as illustrated in Fig. 1-c $\left(\mathrm{A}_{\mathrm{cl}}, \mathrm{B}_{\mathrm{cl}}, \mathrm{C}_{\mathrm{cl}}, \mathrm{D}_{\mathrm{c} 1}\right.$ and $\left.\mathrm{E}_{\mathrm{cl}}\right)$. The coils of the phase $A$ are not represented in the figure since it is the phase where the fault will occur.

The main parameters of the five-phase PMSM useful for the vector control are given in table I. The characteristic shape of its back-EMF is depicted in Fig.2: the third harmonic is about $12 \%$ of the first harmonic.

For classical Maximum Torque Par Ampere (MTPA) vector control, the considered harmonics of currents are only the same as those of emf. Currents are expressed by (1):

$$
i_{j}(t)=I_{1} \cos \left(p \Omega t-(j-1) \frac{2 \pi}{5}-\varphi_{1}\right)+I_{3} \cos \left(3\left(p \Omega t-(j-1) \frac{2 \pi}{5}\right)-\varphi_{3}\right)
$$

Where $\Omega$ is the mechanical frequency, $p$ the pole pairs, $\left(I_{1}, I_{3}\right)$ are the magnitude of the first and the third harmonic current amplitude, $\varphi_{1}$ (respectively $\varphi_{3}$ ) is the phase shift between the first (respectively third) harmonic of current and the first (respectively third) harmonic of the emf. Then, the delivered torque can be expressed as follows:

$$
T_{e m}=\frac{5}{2 \Omega}\left(E_{1} I_{1} \cos \left(\varphi_{1}\right)+E_{3} I_{3} \cos \left(\varphi_{3}\right)\right)
$$

\section{DEFINITION OF CONTROL STRATEGIES IN PRE-FAUlT And Post-Fault Operation Modes}

In this section, the control strategies applied to the fivephase PMSM, in pre-fault and in post-fault operation modes, are summarized. For sake of simplicity, regardless the operating conditions, the first choice in this work is to keep the same structure of the controllers in all operation modes. As consequence, the reconfiguration of the drive system after the fault occurrence consists essentially in modification of the references considering the minimization of both torqueripples and copper losses. Accordingly, the comparative study will be achieved for four different modes as below:

- Healthy mode $\left(M_{1}\right)$ : it corresponds to the MTPA control under healthy operating conditions. It will be considered as reference mode for the temperatures.

- Opened-phase operation mode without reconfiguration $\left(M_{2}\right)$ : although the fault occurrence in the PMSM, the same reference currents are kept as in normal mode operation.

- Opened-phase operation mode with reconfiguration $\left(M_{3}\right)$ : in this case, the reconfiguration strategy consists in minimizing the copper losses for a given torque without imposing any constraint on the current.

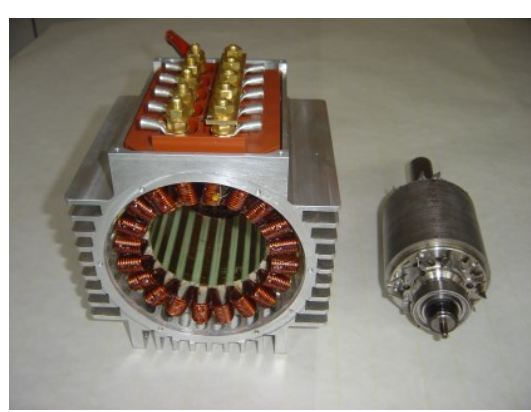

(a)

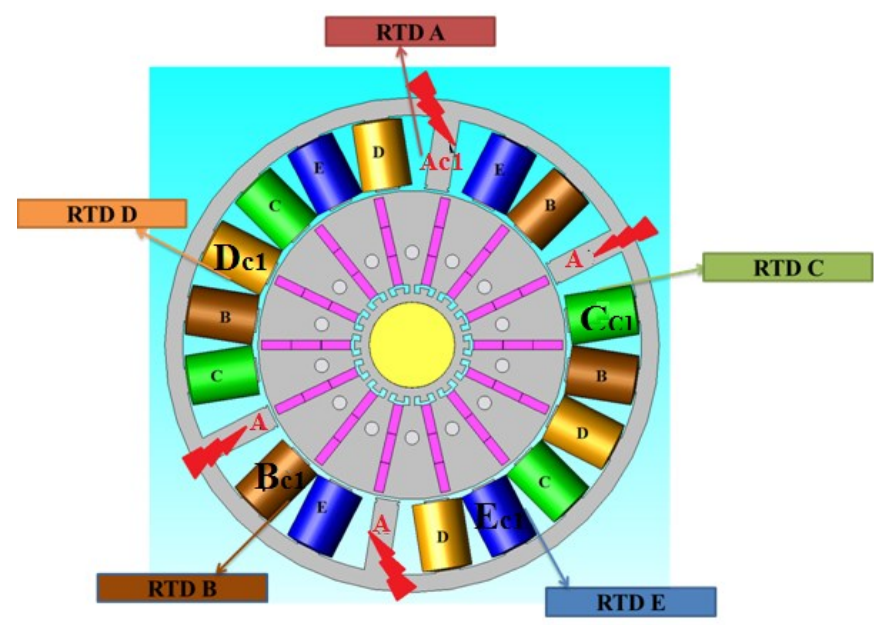

(b)

Fig.1. Motor prototype (5-Ф 20-slot/14-pole). (a) stator/rotor (b) Resistance thermal detector (RTD) location and the faulty coils location.
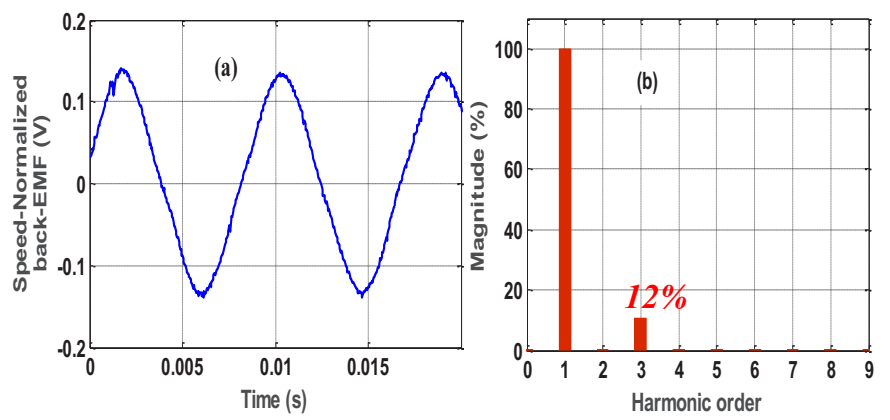

Fig. 2. Experimental speed-normalized (1 $\mathrm{rd} / \mathrm{s})$ EMF and associated spectrum

TABLE I

MAIN ELECTRICAL PARAMETERS OF THE STUDIED 20-SLOT/14POLE 5- $\Phi$ PMSM

$R s=0.091 \Omega ; L p=0.12 \mathrm{mH} ; \mathrm{Ls}=0.05 \mathrm{mH}, p=7$,
$I_{\text {peak }}=180 \mathrm{~A}$, DC-bus voltage $=48 \mathrm{~V}$, Maximum Torque $=50 \mathrm{~N} . \mathrm{m}$.

- Opened-phase operation mode with reconfiguration $\left(M_{4}\right)$ : this one consists in minimizing the copper losses but the currents must be sinusoidal and of equal amplitude in the healthy phases verifying voltage and current limits.

The $M_{3}$ and $M_{4}$ strategies can be only applied after the detection of fault is achieved. Then the $M_{2}$ strategy is 
implicitly used before the adoption of a reconfiguration. The $M_{4}$ strategies have been studied for induction machine [6] and PM machines [7]-[8].

For the experimental results, the working point corresponds to copper losses of around $250 \mathrm{~W}$ in healthy mode $\left(M_{1}\right)$ and a mechanical power of $2.5 \mathrm{~kW}$. In post-fault operation strategies $\left(M_{2}, M_{3}\right.$ and $\left.M_{4}\right)$, the reference currents are modified so that the same global copper losses remain unchanged $(250 \mathrm{~W})$ and the torque is then reduced.

\section{A. Maximum Torque Per Ampere control in pre-fault operation mode ( $M_{1}$ strategy)}

For the system under study, in pre-fault operation mode $\left(M_{l}\right)$, the MTPA strategy is correctly achieved when the two following conditions are respected:

$\checkmark$ Based on equation 2, the phase-shift between current harmonic and the same harmonic in the back-EMFs is zero:

$$
\varphi_{1}=\varphi_{3}=0
$$

$\checkmark \quad$ The ratio of the third current harmonic component and the first one is the same as the ratio between the third harmonic and the first one of the backEMFs. It is defined as follows

$$
\rho=\frac{E_{3}}{E_{1}}=\frac{I_{3}}{I_{1}}
$$

Taking into account (3) and (4), for a given RMS current value $I_{\text {rms }}$, the amplitude of the first and the third current harmonic components are given by:

$$
\left\{\begin{array}{l}
I_{1}=\sqrt{2} \frac{I_{r m s}}{\sqrt{1+\rho^{2}}} \\
I_{3}=\sqrt{2} \frac{I_{r m s}}{\sqrt{1+\rho^{2}}}
\end{array}\right.
$$

The time-domain waveforms of the motor phase currents in MTPA strategy (mode $M_{1}$ ) are illustrated in Fig.3-a. The motor phase currents are normalized with respect to the current peak value. As about $12 \%$ of third harmonic current in injected in this case in phase with the emf, the peak value is about $112 \%$ of peak value of the first harmonic current. Fig.3$\mathrm{b}$ presents their spectrogram in one out of five windings.

\section{B. Maximum Torque Per Ampere control under a faulty condition ( $M_{2}$ strategy)}

As announced above, this mode corresponds to an openedphase fault in the PMSM without reconfiguration. Therefore, the same control is kept and the copper losses are maintained equal to those achieved in pre-fault operation mode by experimental fitting of the current references. The timedomain waveforms of the motor phase currents, normalized

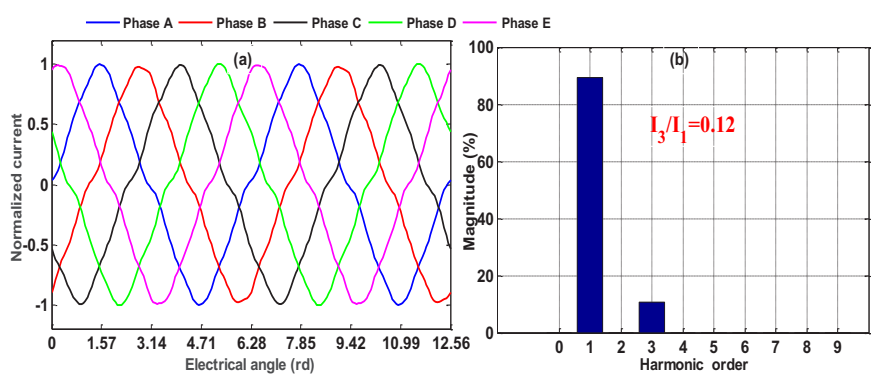

Fig. 3. Time-domain waveforms of the phase currents for the MTPA control $\left(\mathrm{M}_{1}\right.$ strategy) under a healthy operation mode of the five-phase PMSM.

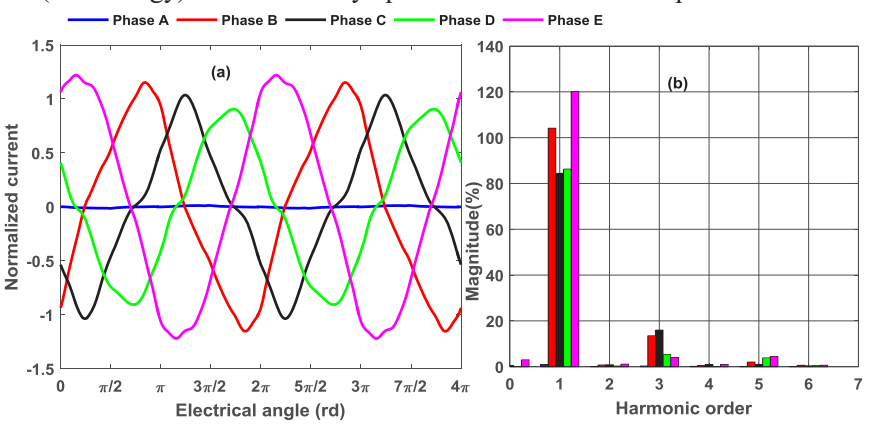

Fig. 4.Time-domain waveforms of the motor phase currents for the MTPA control without reconfiguration $\left(M_{2}\right.$ strategy) under an opened-phase fault (phase $a$ is opened $i_{a}=0$ ).

with respect to the peak value obtained in pre-fault mode, are illustrated in Fig. 4-a.The open-phase fault occurrence results in different modification of harmonic components in the healthy phase-currents (phase $b, c, d, e$ ), since the variation of their magnitudes are not the same. This means that the fault is not equally divided between the healthy phases. In these conditions, a current peak value of about $120 \%$ is reached in the phase $\mathrm{E}$ (in comparison to the one obtained in pre-fault mode).

\section{FTC control strategies}

Two different post-fault tolerant control strategies are addressed when an opened-phase occurs in the five-phase PMSM. The motor phase currents obtained for both FTC strategies $\left(M_{3}\right.$ and $\left.M_{4}\right)$ are normalized with respect to the current peak value obtained in a healthy mode.

1) FTC control with minimum copper losses (Ms strategy):

The generation of the optimal reference currents is performed so that a constant torque (with minimum ripples) must be obtained in post-fault operation mode. For this, the dimension of the current vector is adapted to the dimension of the accessible back-EMF vector with a minimization of the total joule losses as an optimisation criterion. From [13], the optimal reference current vector and the corresponding waveforms in the healthy phases are given by formula (6):

$$
\vec{i}^{*}=\frac{\vec{\varepsilon}^{a c c}}{\left\|\vec{\varepsilon}^{a c c}\right\|^{2}} T^{*}
$$

where $\vec{\varepsilon}^{a c c}$ denotes the normalized-speed accessible backEMF vector [13], $T^{*}$ is the desired torque. Fig.5 depicted the 
time-domain waveforms of the motor phase currents with their harmonic content. Imposing the global copper losses leads easily to the Torque reference $T^{*}$.

2) Strategy with sinusoidal current injection (strategy $M_{4}$ ): in comparison to FTC control proposed in $M_{3}$, this strategy consists in minimizing the joule losses but injecting only sinusoidal references currents. This approach aims to balance power in all healthy phases. The reference currents which must be injected are defined by [6], [8]:

$$
\begin{aligned}
& i_{b}(t)=-i_{d}(t)=\sqrt{2} I_{o p t} \sin \left(p \Omega t-\frac{\pi}{5}\right) \\
& i_{c}(t)=-i_{e}(t)=\sqrt{2} I_{o p t} \sin \left(p \Omega t-\frac{4 \pi}{5}\right)
\end{aligned}
$$

Since the copper losses are the same as in the healthy operation mode $(250 \mathrm{~W})$, we have to add a constraint concerning the copper losses in this machine in order to determine $I_{\text {opt }}$.

$$
P_{j}=4 R_{S} I_{o p t}^{2}=250 \mathrm{~W}
$$

The time domain waveforms of phase currents corresponding to this control strategy are depicted in Fig.6. It appears that the currents introduced in the healthy phases are sinusoidal and with equal amplitude.

\section{COMPARATIVE ANALYSIS}

In this section, a comparative evaluation between the four control modes $\left(M_{1}, M_{2}, M_{3}, M_{4}\right)$ is presented. It is achieved regarding the following criteria:

$\checkmark$ The average delivered torque.

$\checkmark$ The torque ripples.

$\checkmark \quad$ The peak voltage value required by the PMSM.

$\checkmark \quad$ The peak current value.

\section{A. Torque and voltage/current peak behavior}

The comparative analysis between different control strategies presented above is achieved. It is based on Finite Element (FE) model simulation. Therefore, the obtained timedomain current waveforms are injected into the FE model of the five-phase PMSM.

Fig.7 illustrates FE simulation results of the comparison between the different control strategies.

1) Torque average value: Comparing the results in Fig.7-a, it can be seen that, except for the normal operation mode in which the torque is equal to $32.5 \mathrm{~N} . \mathrm{m}$, the torque average value is about $26 \mathrm{~N} . \mathrm{m}$ ( $80 \%$ of torque corresponding to the mode $M_{1}$ ) in post-fault operation when the copper losses is kept equal to $250 \mathrm{~W}$.

2) Torque ripple: under healthy operation mode of the PMSM (mode $M_{1}$ ), the machine generates a quite smooth torque. On contrary, under faulty operating conditions corresponding to an opened-phase fault (mode $M_{2}$ ), a large dissymmetry is introduced in the motor, resulting in high torque ripples equal

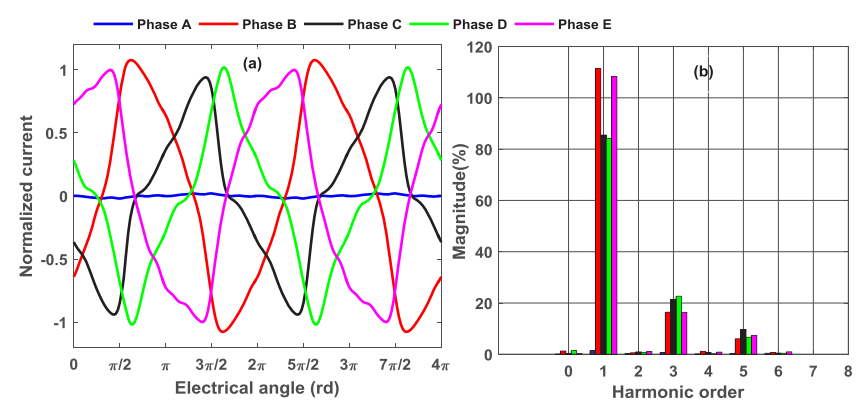

Fig. 5. Time-domain waveforms of the motor phase currents with reconfiguration ( $M_{3}$ strategy) under an opened-phase fault (phase $a$ is opened

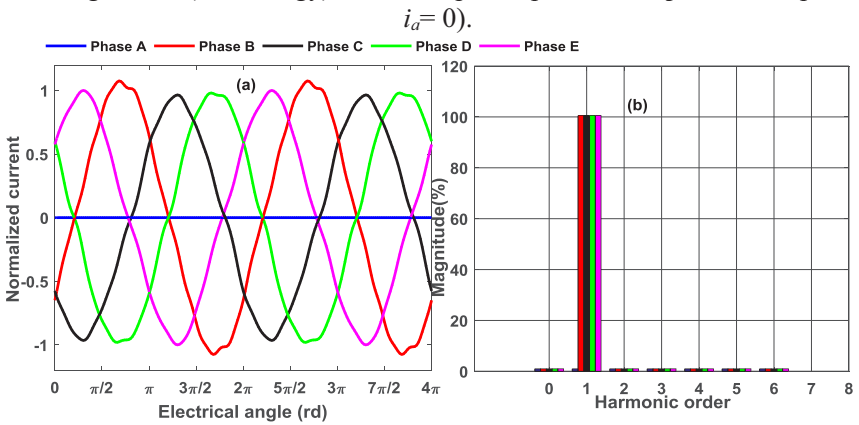

Fig. 6. Time-domain waveforms of the motor phase currents with reconfiguration $\left(M_{4}\right.$ strategy) under an opened-phase fault (phase $a$ is opened $\left.i_{a}=0\right)$.

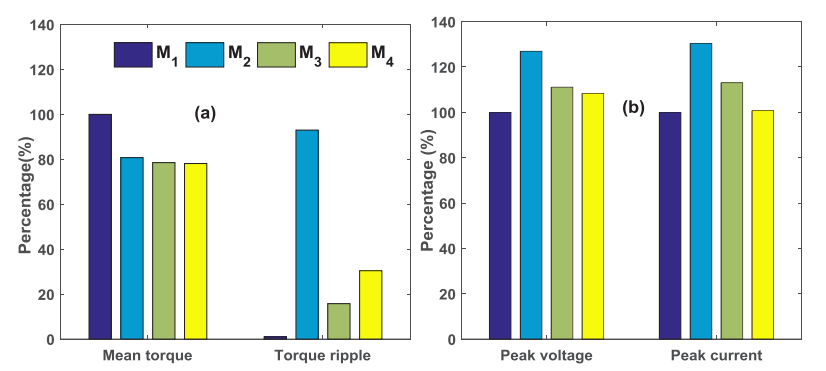

Fig. 7. Parameters of comparison between the healthy mode control strategy and post-fault control strategies.

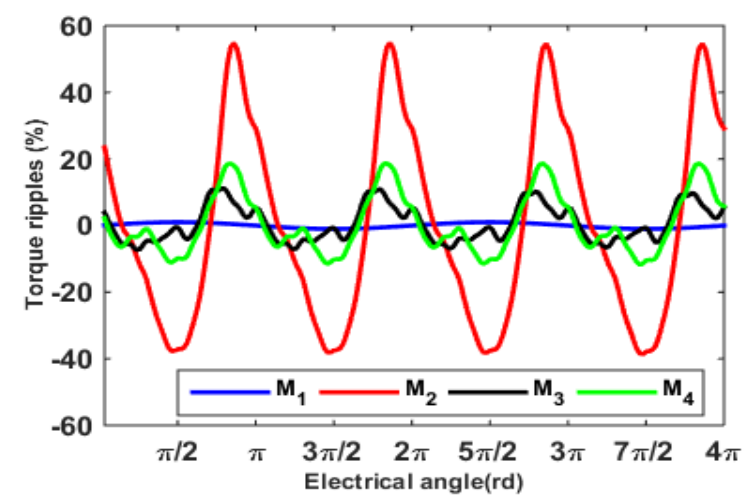

Fig. 8. Torque ripples calculated by FE simulations normalized with respect to the mean value for each operation mode.

to $93 \%$, as shown in Fig.8. Thanks to FTC, strategies $M_{3}$ or $M_{4}$, an acceptable ripples level of the torque is obtained. It is important to point out that the constraint of sinusoidal supply as achieved only in mode $M_{4}$ resulting in torque ripples $30 \%$ 
larger than the ripples obtained for FTC control of mode $M_{3}$ (14\%) as shown in Fig.7-a and Fig.8.

3) Required peak voltage: as shown in Fig.7-b, with regard to mode $M_{2}$, it can be concluded that the fault induces a high voltage peak value of $130 \%$ in comparison to the normal operation mode of the motor. Applying the fault tolerant control strategies corresponding to the modes $M_{3}$ and $M_{4}$, the voltage peak value are kept relatively low approximately near $115 \%$.

4) Peak current: as for the required voltage, strategies ( $M_{3}$ and $M_{4}$ ) required low peak current than $M_{2}$ for the same amount of torque. In conclusion, the reconfiguration of control in postfault operation modes is important in order to reduce the required voltage/current for a given torque.

\section{B. Copper losses comparison and thermal behavior analysis}

As discussed above, the voltages and currents distortion in post-fault operation modes affects the performance of the fivephase PMSM. In fact, the non-sinusoidal supply applied to the PMSM results in various harmonic components circulation in motor windings. Consequently, high frequency electric components produce additional losses, increasing thus the operating temperature of the windings as well as the core. These conditions result in degradation of the performance.

Fig.9 summarizes the normalized copper losses in each phase when the considered control strategies are applied. The results are normalized with respect to the value of the copper losses per phase, equal to $50 \mathrm{~W}$, corresponding to the healthy operation mode of the five-phase PMSM.

In post-fault operation mode, the $250 \mathrm{~W}$ of copper losses are distributed between the remaining healthy phases, either equally as in modes $M_{1}$ and $M_{4}$ or non-equally as in mode $M_{2}$ and $M_{4}$. The post-fault operation modes create nonhomogenous distribution of losses in the motor windings. As the temperature is directly related to losses, the nonhomogeneity of the losses distribution impacts significantly the temperature difference between the motor phase windings. As there are no copper losses in the faulty phase, it is expected that it has the lowest temperature value.

According to Fig.9, phases $\mathrm{C}$ and D have almost identical copper losses in all the considered operation modes $\left(M_{1}, M_{2}\right.$, $M_{3}$ and $\left.M_{4}\right)$. In addition, the phase $\mathrm{E}$ has the greater copper losses in post-fault operation mode $\left(M_{2}, M_{3}\right.$ and $\left.M_{4}\right)$. Then, it is expected that this phase will have the highest temperature among the five phases when an open circuit fault occurred in phase A. The temperature measurement analysis detailed in section $\mathrm{V}$ confirms these conclusions.

\section{Thermal Test And AnAlysis For Control Strategie}

\section{A. Thermal environment and cooling of the machine}

The presented machines is equipped by two external fans sticked on both sides of the rotor, and are designed to ensure an efficient cooling of the end-windings as illustrated in Fig.1a. Furthermore, fins are present at the bottom, right and left sides of the motor cover as observed in Fig.1-a. At these sides of the machine, the cooling with natural ventilation is enhanced. However, the connexion box is fixed on the top of

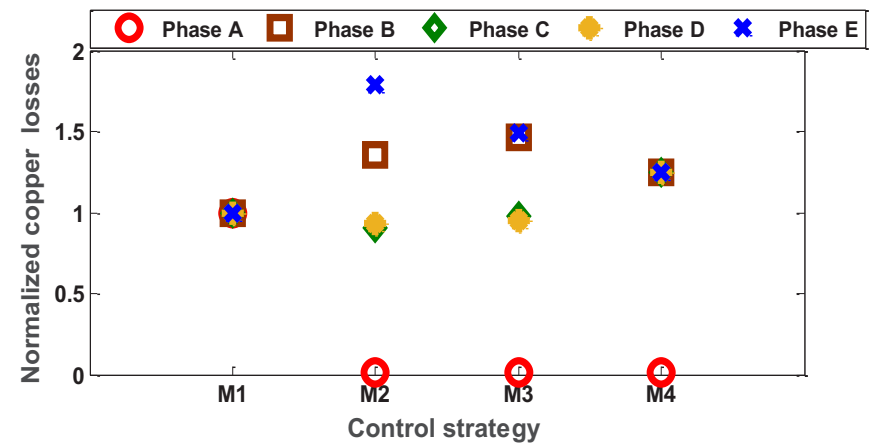

Fig. 9.Variation of copper losses in each phase for each control strategy.

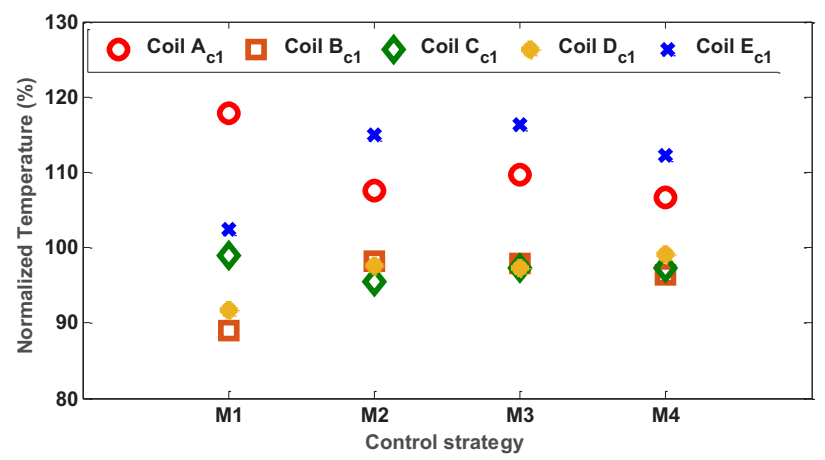

Fig. 10.Normalized temperature measured for a coil of a phase. The values are normalized with respect to the mean value of the temperature in healthy mode operation $\left(M_{l}\right)$.

the machine, which makes less efficient the cooling by the natural ventilation in this side. The presented cooling circuit of the machine have a noticeable impact on the temperature repartition.

Temperature probes are inserted into the machine according to Fig. 1-b. All these probes are placed within the slot, in contact with the copper. The resistance thermal detectors (RTD) are linked to a data acquisition system that allowed plotting the temperature versus time curve for each detector. The temperature measured in steady state is normalized with respect to the mean value of the temperature in healthy mode operation $\left(M_{1}\right)$, which equal to $111^{\circ} \mathrm{C}$. Results are illustrated in Fig. 10.

\section{B. Analysis of temperature measurement}

In healthy operation mode $M_{l}$, the measured temperatures are not identical between all the phases as shown in Fig.10, although the copper losses are the same in these phases. There is up to $30 \%$ of difference. The first remark is that it is not obvious to consider the temperature of a phase which is obtained with several windings. For example, in the phase A the coil $\mathrm{A}_{\mathrm{c} 1}$ has the highest temperature. Thermal analysis shows that it is due mainly to the connexion box (see Fig.1-a) whose thermal resistivity is higher than for the other coils which are near fins.

In fault mode configuration it can be observed that the repartition is of course different for the different modes but even if there is no more current in phase $\mathrm{A}$, the temperature of 
the coil $A_{c 1}$ is still higher than in the healthy phases. As consequence the choice to keep the same Joule Losses in the remaining healthy phases is an adequate criterion in terms of thermal goal.

\section{CONCLUSION}

This paper shows that in fault mode, the strategy which consists in imposing the same Joule losses in the remaining healthy phases does not lead to equal temperatures in the healthy phases and even more the temperature in winding of opened phase is not the weakest. A hot point can appear. As consequence in order to able to reduce the security margins concerning the temperatures in windings, it should be interesting to define new strategies based on temperature measurements and a thermal modelling of the machine: in each phase, admissible Joule losses and waveform of current could be chosen in order to obtain the maximum possible average torque under constraints of peak voltage and peak current. This kind of approach will be particularly interesting for drive in transportation since transient operation as acceleration phase during less than 60 s are often required. In this case the repartition of the temperatures is of utmost importance.

\section{ACKNOWLEDGMENT}

This work has been achieved within the framework of CE2I project. CE2I is co-financed by European Union with the financial support of European Regional Development Fund (ERDF), French State and the French Region of Hauts-deFrance.

\section{REFERENCES}

[1] V. I. Patel, J. Wang, W. Wang, and X. Chen, "Six-phase fractional-slotper-pole-per-phase permanent-magnet machines with low space harmonics for electric vehicle application," IEEE Transactions on Industry Applications, vol. 50, no. 4, pp. 2554-2563, 2014.

[2] X. Huang, A. Goodman, C. Gerada, Y. Fang, and Q. Lu, "Design of a five-phase brushless dc motor for a safety critical aerospace application," IEEE transactions on industrial electronics, vol. 59, no. 9, pp. 3532-3541, 2012.

[3] J. Haylock, B. Mecrow, A. Jack, and D. Atkinson, "Operation of a fault tolerant pm drive for an aerospace fuel pump application,'IEEE Proceedings-Electric Power Applications, vol. 145, no. 5, pp. 441-448, 1998.
[4] L. Parsa and H. A. Toliyat, "Five-phase permanent magnet motordrives for ship propulsion applications," Electric Ship Technologies Symposium, 2005 IEEE , pp. 371-378, IEEE, 2005.

[5] S. Williamson, S. Smith, and C. Hodge, "Fault tolerance in multiphase propulsion motors," Journal of Marine Engineering \& Technology, vol. 3, no. 1, pp. 3-7, 2004.

[6] J.-R. Fu and T. A. Lipo, "Disturbance-free operation of a multiphase current-regulated motor drive with an opened phase," IEEE Transactions on Industry Applications, vol. 30, no. 5, pp. 1267-1274, 1994.

[7] F. Baudart, B. Dehez, E. Matagne, D. Telteu-Nedelcu, P. Alexandre and F. Labrique, "Torque Control Strategy of Polyphase Permanent-Magnet Synchronous Machines With Minimal Controller Reconfiguration Under Open-Circuit Fault of One Phase," IEEE Transactions on Industrial Electronics, vol. 59, no. 6, pp. 2632-2644, June 2012.

[8] O. Fall, N. K. Nguyen, J. F. Charpentier, P. Letellier, E. Semail, and X. Kestelyn, "Variable speed control of a 5-phase permanent magnet synchronous generator including voltage and current limits in healthy and open-circuited modes," Electric Power Systems Research, vol. 140, pp. 507-516, 2016.

[9] N. Bianchi, S. Bolognani, M. Dai Pre, and E. Fornasiero, "Post-fault operations of five-phase motor using a full-bridge inverter," Power Electronics Specialists Conference (PESC) 2008, pp. 2528-2534.

[10] J. Wang, K. Atallah and D. Howe, "Optimal torque control of faulttolerant permanent magnet brushless machines, "IEEE Transactions on Magnetics, vol. 39, no. 5, pp. 2962-2964, Sept. 2003.

[11] S. Dwari, L. Parsa, "An optimal control technique for multiphase PM machines under open-circuit faults, "IEEE Transactions on Industrial Electronics, vol.55, no.5, pp.1988-1995, May 2008.

[12] F. Locment, E. Semail and X. Kestelyn, "Vectorial Approach-Based Control of a Seven-Phase Axial Flux Machine Designed for Fault Operation," IEEE Transactions on Industrial Electronics, vol. 55, no. 10, pp. 3682-3691, Oct. 2008.

[13] X. Kestelyn and E. Semail, "A vectorial approach for generation of optimal current references for multiphase permanent-magnet synchronous machines in real time," IEEE Transactions on Industrial Electronics, vol. 58, no. 11, pp. 5057-5065, 2011.

[14] N. Bianchi, E. Fornasiero, and S. Bolognani, "Thermal analysis of a five-phase motor under faulty operations," IEEE Transactions on Industry Applications, vol. 49, no. 4, pp. 1531-1538, 2013.

[15] F. Baneira, J. Doval-Gandoy, A. G. Yepes, Ó. López and D. PérezEstévez, "Control Strategy for Multiphase Drives With Minimum Losses in the Full Torque Operation Range Under Single Open-Phase Fault, ' IEEE Transactions on Power Electronics, vol. 32, no. 8, pp. 6275-6285, Aug. 2017.

[16] B.Aslan, E. Semail, J.Korecki and J. Lagranger, "Slot/pole combinations choice for concentrated multiphase machines dedicated to mild-hybrid applications." IECON 2011-37th Annual Conference on IEEE Industrial Electronics Society. IEEE, 2011. p. 3698-3703. 